\title{
The problem of mechanical compatibility of natural building stones in the restoration of monuments. Part II: Specimens with modified boundaries
}

\author{
Nikolaos L. Ninis ${ }^{1}$ and Stavros K. Kourkoulis ${ }^{2, *}$ \\ ${ }^{1}$ Finance Management Fund for Archaeological Projects, \\ Ministry of Culture and Tourism, Athens, Metsovou 33, \\ GR 106 82, Ligourio, Greece \\ ${ }^{2}$ Department of Mechanics, National Technical University \\ of Athens, School of Applied Mathematical and Physical \\ Sciences, Theocaris Building, Zografou Campus, GR 157-73 \\ Athens, Greece, e-mail: stakkour@central.ntua.gr \\ * Corresponding author
}

\begin{abstract}
It was pointed out in Part I of this short two-paper series, that the mechanical incompatibility between the authentic building stone of ancient monuments and the stones used as substitute ones during restoration projects, may be the reason of violation of basic restoration principles concerning the protection of the ancient material. In this context certain geometrical configurations of the boundaries of the specimens are examined in this Part II as a possible means of modifying the mechanical behaviour of the substitute stones, in order to make them as compatible as possible with the authentic material. Modifications of both the contact surfaces (in order to change the friction conditions) of the specimens as well as of the free ones (in order to quantify the influence of transforming the smooth cylindrical surface to a fluted one) are examined experimentally. This approach is based on existing observations and numerical studies indicating that the behaviour of a stone specimen in the post-peak region is affected by the geometrical configuration of its boundaries. Taking advantage of the experimental results an alternative compatibility criterion is introduced for situations where the "required" quality of the building stone is its ability to withstand deformation without failing structurally, a characteristic pertinent to statically indeterminate structures, whose design is based on deformation control. This criterion combines both peak stress and maximum failure strain providing a better insight into the problem of mechanical incompatibility of natural building stones.
\end{abstract}

Keywords: compatibility; compression; friction; monuments; natural building stones; porous stones; restoration; soft rocks.

\section{Introduction}

The problem of the mechanical compatibility of natural building stones was studied experimentally in Part I [1] of the present short two-paper series. The study was focused on the stone of Kenchreae extensively used by ancient Greeks for the erection of the monuments of the Asklepieion at Epidauros. The motive of the work was the need of the scientists working for the restoration of these monuments to assess the suitability of various natural building stones that could be used as substitutes of the authentic one either for the completion of damaged ancient structural members or even for the complete reconstruction of missing ones. Indeed for reasons beyond the will of the scientific committee responsible for the restoration project of the Epidaurean monuments, it has been proved impossible to obtain fresh authentic stone from the wider area of the ancient quarries [2] and therefore the use of substitute stones appears to be indispensable.

The methodology adopted in Part I was based on the use of composite specimens, either cylindrical or prismatic, consisting of equidimensional parts of two different stones, subjected to unconfined uniaxial compression. It was proved that certain configurations exist for which the incompatibility of the constituent parts could lead the authentic stone to premature failure violating basic restoration principles. In this context certain geometrical configurations of the boundaries of the specimens that could modify the mechanical behaviour of building stones (making them as compatible as possible with the authentic material) are examined in this Part II. This approach is based both on existing experimental results and in situ observations and also on numerical analyses according to which the mechanical behaviour of a cylindrical stone specimen under unconfined compressive loading is crucially affected (at least in the post-peak region of the axial stress-axial strain diagram) by the geometrical configuration of its contact - as well as its free - boundaries [3, 4].

\section{Experimental procedure}

\subsection{The experimental set-up}

Series of uniaxial compression tests were carried out with the aid of a stiff hydraulic Amsler loading frame of capacity $1000 \mathrm{kN}$. Taking into account that the maximum load did not exceed in any case $45 \mathrm{kN}$, it is concluded that the stiffness of the frame can be considered infinite, which is of vital importance if the post-peak behaviour of the material is to be studied. The load was applied statically at a rate not exceeding $10^{-2} \mathrm{~mm} / \mathrm{min}$. It is to be emphasised here, that the loading rate is a very important parameter in testing natural building stones and geomaterials in general. The results of a series of commercially tests for the same materials but at higher strain rates [5], listed in Table 1, are very far from the results of the quasi-static tests described in previous paragraphs and listed in table 3 of Part I [1]. 
Table 1 Peak stress of the authentic and substitute materials as obtained from commercial tests.

\begin{tabular}{ll}
\hline Stone & Compressive strength (MPa) \\
\hline Kenchreae & $7.4-21.9$ \\
Crete (Alfopetra compact) & 23.8 \\
Cyprus & 42.2 \\
Zakynthos & $51.1-76.2$ \\
\hline
\end{tabular}

Special care was taken to ensure that the bases of the cylinders were parallel to each other and perpendicular to the load direction. For this purpose a special set-up was designed permitting cover of the bases of the specimens with a thin layer of steel-putty eliminating the imperfections created by the cutting tool during the preparation of the specimens and producing smooth surfaces perpendicular to the loading axis. In addition a special semi-spherical head interposed between the loading plate and the moving piston ensured further the co-axiality between the load and the axis of the specimen (Figure 1A).

For the measure of displacements six LVDTs of sensitivity equal to $10^{-6} \mathrm{~m}$ were used. Three of them were used for the measure of axial displacements and were placed at $120^{\circ}$ to each other in order to check the loading symmetry and the rotation of the loading platens (Figure 1A, B). The remaining three were used for the measure of the transverse displacements. Additionally, in some of the tests a system of four strain-gauge rosettes was used, antidiametrically glued on two mutually perpendicular diameters of the specimens, mainly for comparison reasons and, also, for the accurate determination of Poisson's ratio, since the "point" measurements of the horizontal LVDTs were not taken into account due to the extremely high scattering of the results (Figure 1C).

\subsection{The friction aspect in the measured "element" behaviour}

It is a well-known fact that friction plays an important role in the mechanical behaviour of a specimen subjected to unconfined compression. Parameters, such as peak strength, failure strain at peak, ultimate strength, etc. are all measured at a stage when the specimen has already started to behave nonuniformly, at micro-structural and meso-structural level, resembling more the behaviour of a structure. Labuz and Bridell [6] have demonstrated that the effect of platen lubrication is paramount, while both Drescher and Vardoulakis [7] and Read and Hegemier [8] have pointed out that little can be inferred from nonlubricated tests. Although according to classical theory the end effects in the middle half of the specimen are negligible [9], this is strictly not true unless all measurements could be taken at the middle "uniformly straining" part of the specimen. It is thus important to secure during testing that every measure is taken in order to keep straining conditions uniform. Minimising (or eliminating) friction at contact bases is one of them.

Concerning the interface between end-platens and specimen the majority of tests in the present work were carried out using nonlubricated surfaces, in an effort to simulate the real conditions, since the material is to be used in direct contact with existing structural elements of the monument. However, for comparison, additional tests were carried out with minimised friction between the specimens and the loading platens. The minimisation of friction was achieved by inserting two sheets of polytetrafluoroethylene (PTFE), a thick one (thickness $2 \mathrm{~mm}$ ) and a thinner one (thickness $0.5 \mathrm{~mm}$ ), between the platen and the base of the specimen in the series: "Platensthick sheet-thin sheet-specimen's base". A small amount of stearic acid was placed both between the loading platens' surface and the thick PTFE sheet and between the two PTFE sheets. Stearic acid was used since it is very efficient in reducing friction under high loads. The role of the second PTFE sheet (the thin one) was to prevent penetration of stearic acid particles in the pores of the specimen, since in this way transverse strains are developed, which change the stress field. A similar technique was used by van Vliet and van Mier [9] in a research with concrete specimens, and has also been successfully tried with Dionysos marble by Exadaktylos et al. [10] and with conchyliates shellstone by Vardoulakis et al. [11]. It was found to give satisfactory results.
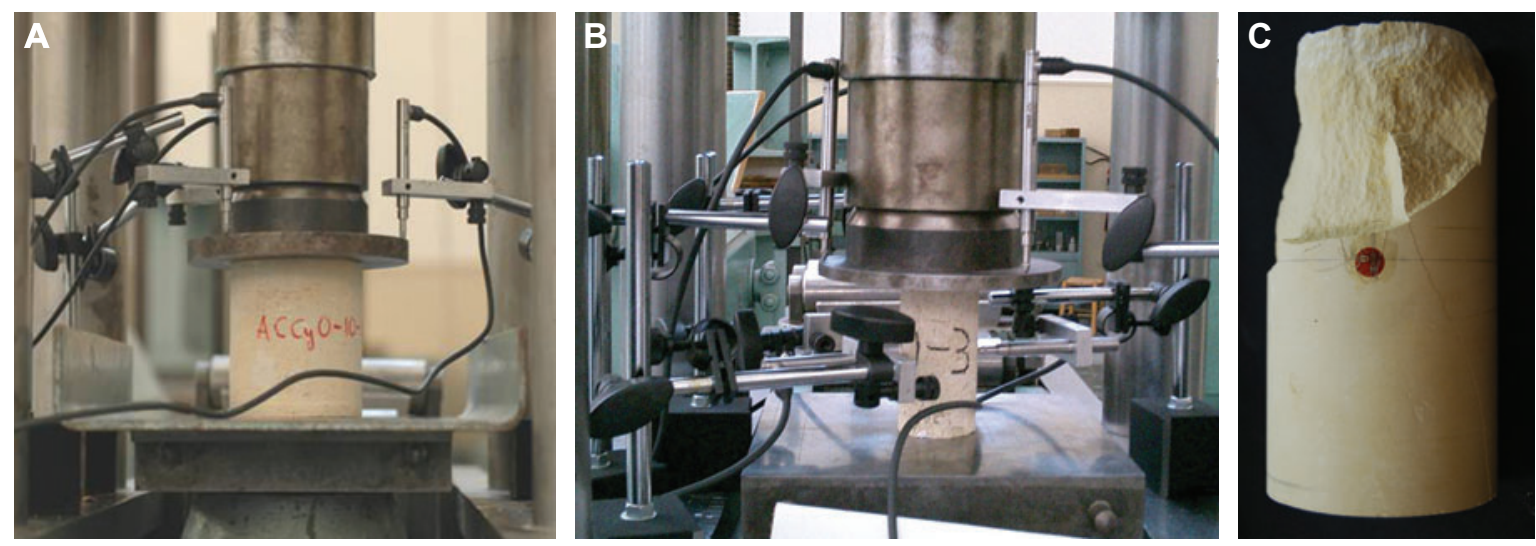

Figure 1 The experimental set-up with only vertical (A) and with vertical and horizontal LVDTs (B) (the indications of the latter were not evaluated due to their scattering). (C) A typical Cyprus stone fractured specimen with strain gauge rosettes. Four rosettes were used at the ends of two mutually perpendicular diameters. 
For the Kenchreae stone the influence of lubrication was of no real consequence since it did not affect neither the strength nor the mode of failure. The same was not true, however, for the proposed substitute materials, for which the use of lubrication changed the failure mode from the familiar one of the Mohr's cones to an almost axial splitting one. This change is a serious problem for the restoration process: although friction can be eliminated in laboratory tests using lubrication, this possibility does not exist in real life situations where any kind of lubricant would become inactive with time. A different approach to the problem would involve modification of the boundary conditions by altering the contact surfaces either by securing near perfect contact only along a perimeter rim, or by substituting the contact base of the specimens with a patch of a softer material. These approaches are analysed in the next paragraph.

\section{Specimens with modified contact boundaries}

In the previous context and based on the results of recent experimental and numerical work according to which the modification of the surface of the compression specimens influences their mechanical behaviour [3, 12] a systematic experimental study of the phenomenon is undertaken here. Specimens made of both authentic and substitute stones with various modifications of their contact bases are tested in an effort to quantify the influence of these modifications on the observed mechanical behaviour.

\subsection{Geometrical configuration of the contact surfaces}

The aim of this series of experiments was the investigation of the influence of geometrically modifying the boundary conditions at the contact bases of the specimens. The idea for the modification (Figure 2) came from the way the bases of column drums in ancient Greek architecture were configured; in them, near perfect contact between adjacent drums was secured only along a perimeter rim, where surface is made as smooth as possible, while the rest of the base is left roughly worked having a greater roughness and a true contact area that can be less than $50 \%$ (Figure 3). The specimens were tested in uniaxial unconfined compression.

The above-described configuration of the bases with contact along a perimeter rim (thickness $10 \mathrm{~mm}$ and height $3 \mathrm{~mm}$ ) resulted in an interesting change of the overall behaviour of the Kenchreae stone, as can be seen in Figure 4 . The stresses were obtained by dividing the externally applied load by the true contact area, i.e., that of the perimeter contact ring. Specimens A and B referred in Figure 4 were of the "ring contact" type while specimen $\mathrm{C}$ was slightly modified since the corners of the ring were smoothened slightly resulting to a "tapered ring contact" specimen. In all cases, the stress-strain curve increases to a peak strength (at a strain level equal to about 0.0024 , roughly $40 \%$ less than that of the normal specimen) after which it drops following local yielding of the material of the ring. The initial response becomes significantly

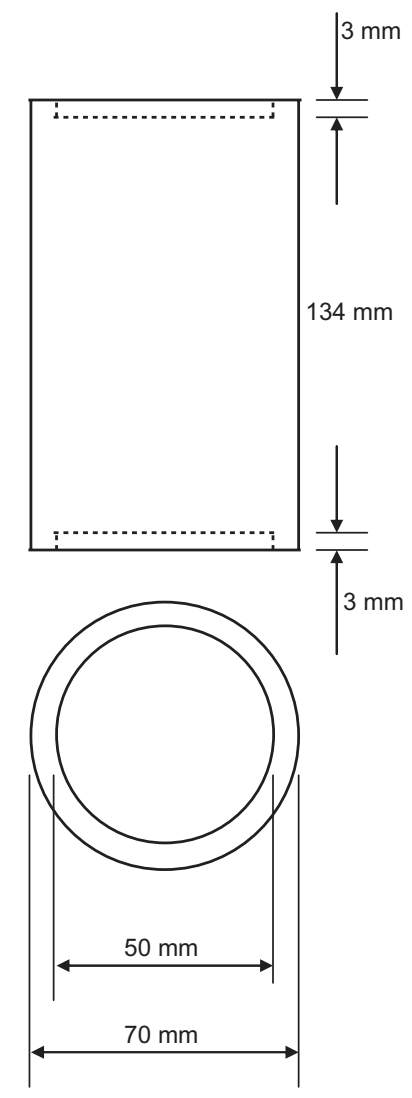

Figure 2 The configuration of the rimmed specimens.

stiffer, by roughly $40 \%$. Specimen C exhibits the most dramatic change: Its maximum strength is practically tripled without affecting the extent of the post-peak region. Characteristic tested specimens of the "ring contact" type made of Kenchreae stone are shown in Figure 5. It is worth mentioning the development of vertical calcite veins during loading at the upper and lower bases of the specimens, which indicate load transfer paths (Figure 5A). These veins are gradually transformed to axial cracks as the specimen is further loaded to failure.

The respective curves for Alfopetra are plotted in Figure 6. As it is seen from this figure, specimens with "tapered ring contact" yield a stiffer initial response and produce a $20 \%$ decrease in terms of maximum strength and ultimate strain. It is very instructive to note at this point that in case the "nominal" stresses are plotted, i.e., the load divided by the total area of the central cross section of the specimen, then the maximum strength obtained (associated with the midsection) reaches the value of about $15 \mathrm{MPa}$, which approaches closely the yield stress of the material as it is obtained from the curve of intact soft Alfopetra stone specimens.

Perhaps the most important outcome of this particular series of tests, at least for the brittle Alfopetra stone, is the complete change in the mode of failure. The development of the familiar Mohr-Coulomb friction cone was totally suppressed and instead the specimens failed by forming vertical cracks on the outer lateral surface, as it is clearly seen in Figure 7. 


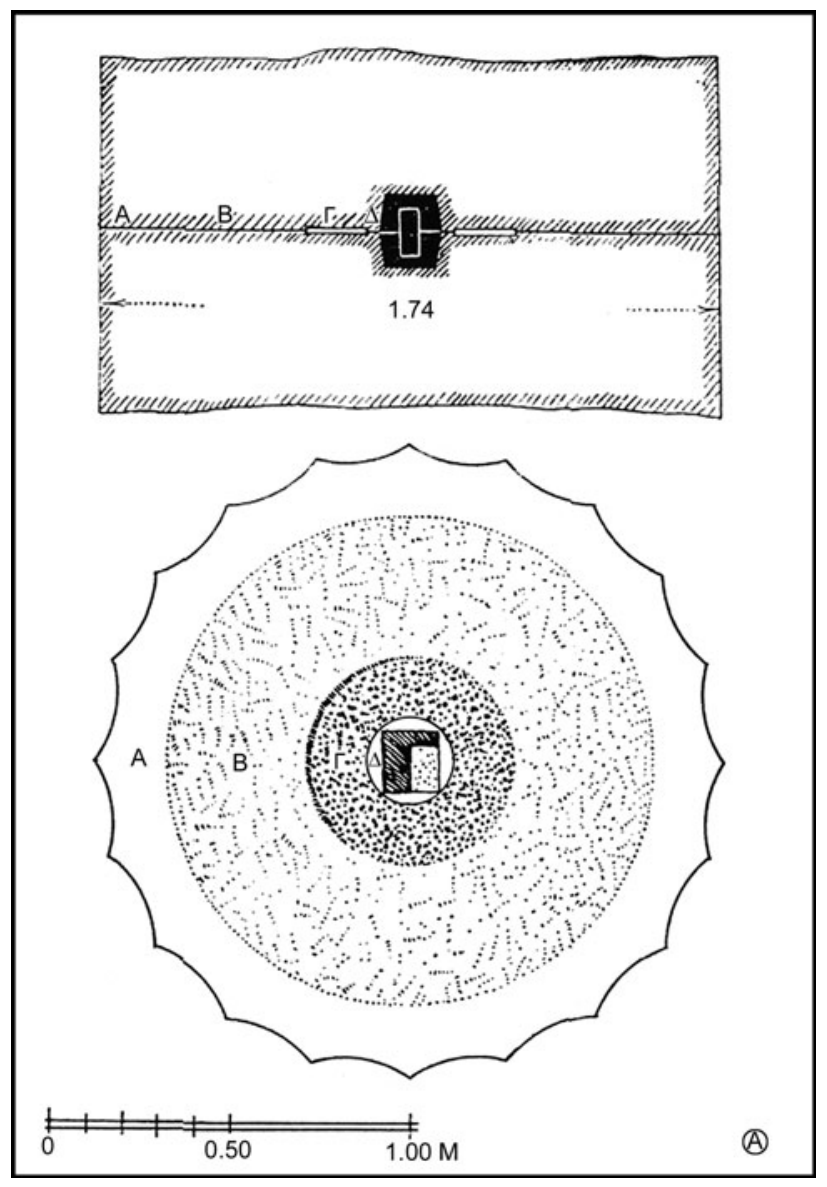

Figure 3 Schematic configuration of a Parthenon column drum base in plan and section.

The main objective of the present series of tests was to study the mechanical strength of some natural building stones, considering the contact between the end-platen and the specimen base as a dry joint and changing the conditions across this boundary so as to better approximate real

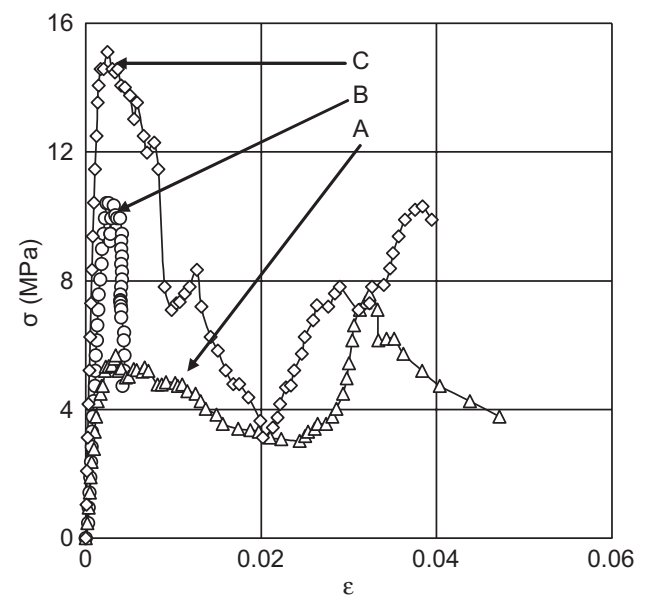

Figure 4 The influence of rimming on the stress-strain curve under uniaxial compression for the Kenchreae stone.
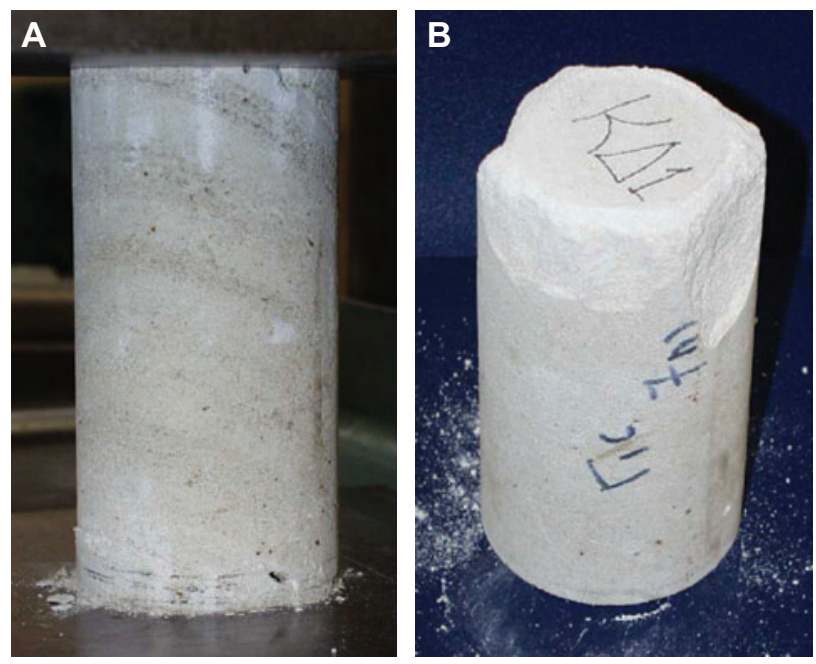

Figure 5 Characteristic tested specimens of the ring type rimming made from Kenchreae stone.

life situations. A direct analogy can be drawn, for example, between the cylindrical specimen used in unconfined compression and the column drum of an ancient temple, which under static conditions is also subjected to the same kind of loading.

It appears that by restricting the contact surface to a narrow ring along the perimeter of the specimen base, the nonuniform distribution of stresses across the base is minimised. The load is transferred along vertical linear paths in the surface. The lateral surface of the specimen is being stressed as a cylinder under plane strain conditions. The results show that exfoliation and fracture are concentrated near the surface and take the form of vertical tension cracks sometimes running the full height of the specimen. The photographs of Figure 7 illustrate clearly the point. The exfoliations seen in these photographs, bears a cunning resemblance to the flutes of a doric column; a number of vertical cracks (usually between seven and 10),

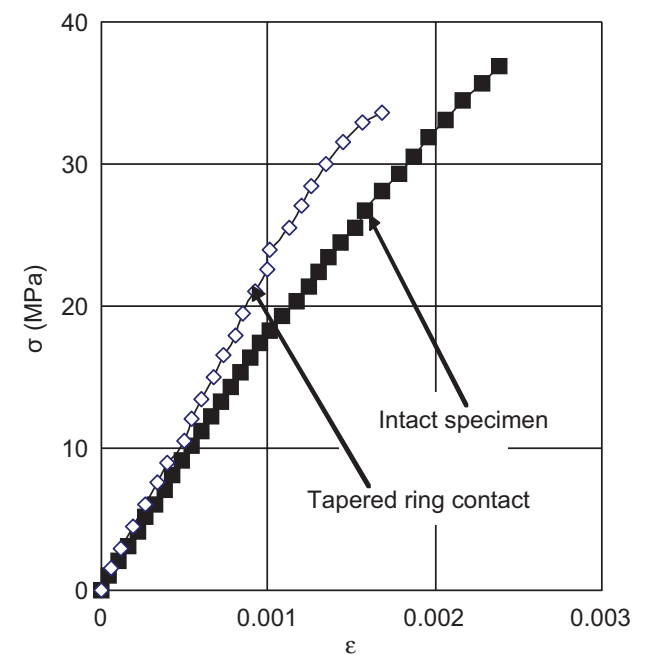

Figure 6 The influence of rimming on the stress-strain curve under uniaxial compression for the Alfopetra stone. 

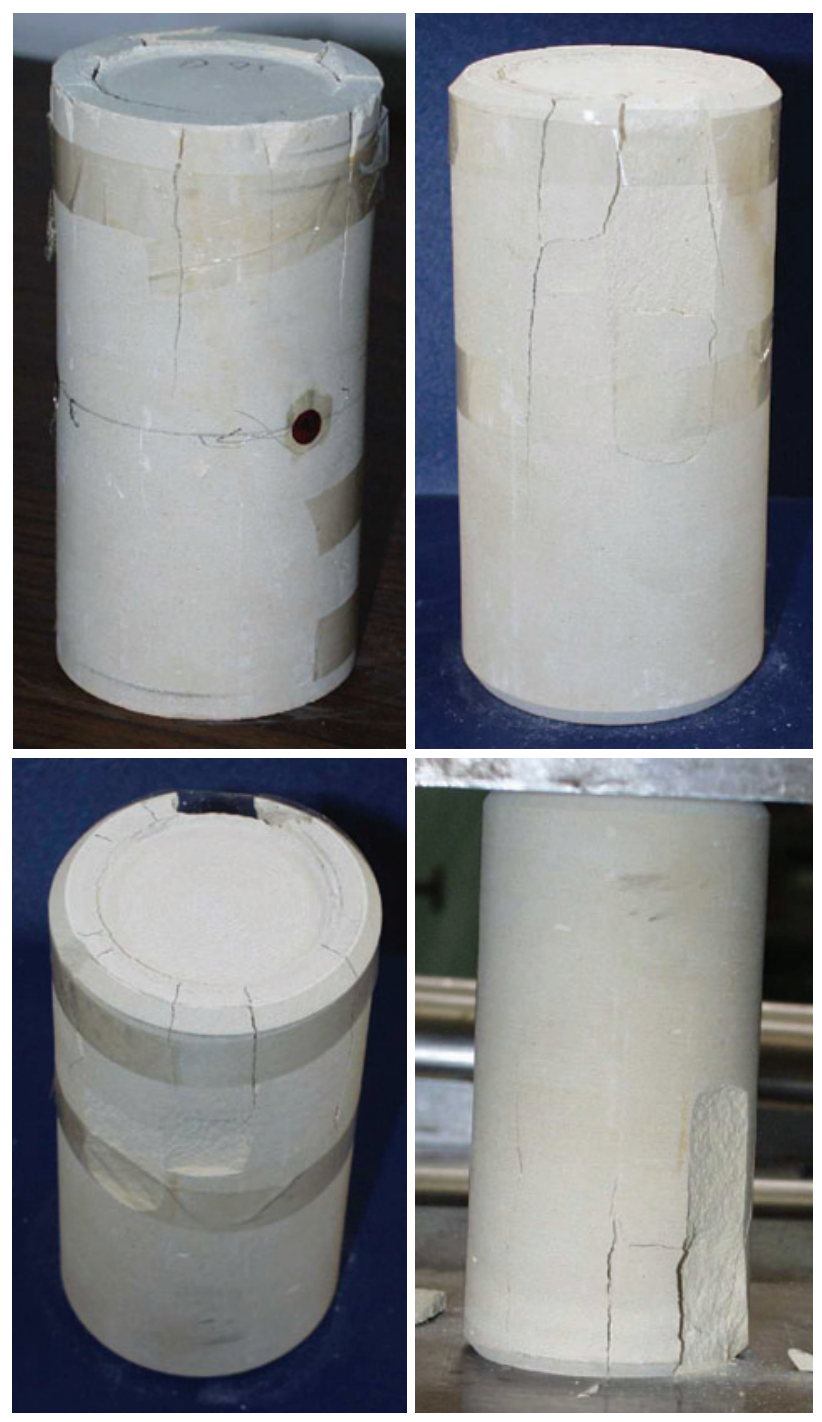

Figure 7 The failure mode of various ring type specimens made from Alfopetra stone.

developing at the base at equal distances along its perimeter, have systematically been recorded during this series of tests as it seen, also, in Figure 8.

By introducing the ring contact at the contact bases it seems that one is able to control the mode of failure and control the "how" and "where" the specimen is going to crack. The effectiveness of such a geometrical modification of the bases is more pronounced in case of brittle materials, where friction effects become dominant. In fact the modification of the bases constitutes a method for eliminating the nonuniform distribution of contact stresses in cases where lubrication cannot be applied.

\subsection{Material configuration}

Another way of affecting the friction regime along the bases is by locally changing the material properties, i.e., by introducing a layer of different material. In practice, this is relevant when, for example, the missing base of a column drum has to

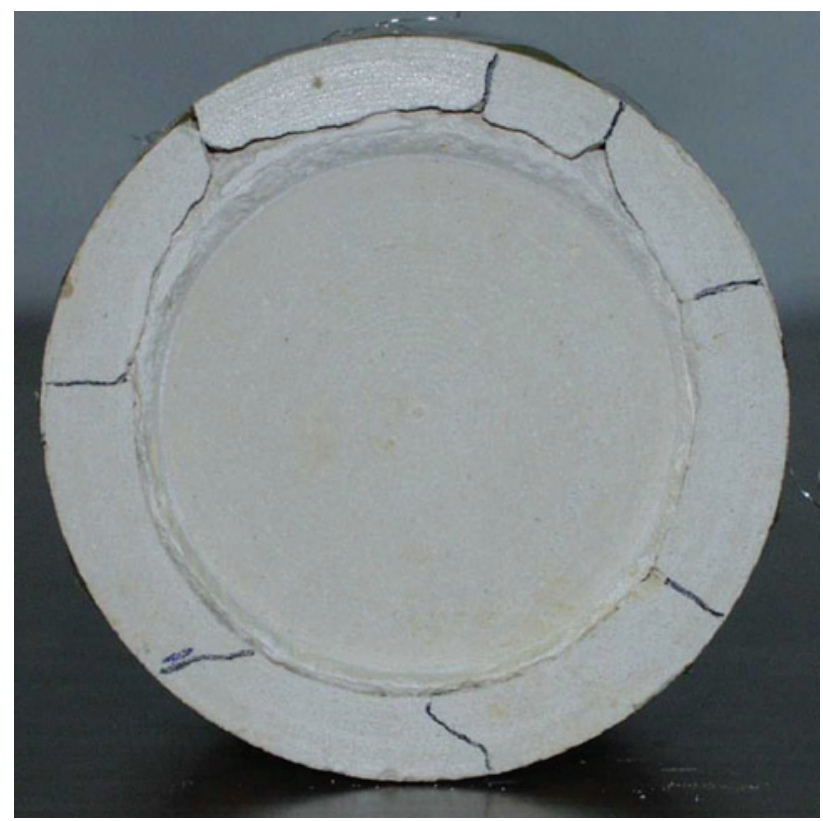

Figure 8 Vertical cracks (seven to 10), developed along the perimeter of the base at almost equal distances from each other.

be completed with new material, be that natural or artificial stone. In order to investigate this case, following the results of a preliminary experimental work [13], a second class of specimens with modified bases is introduced: A thin slice of the specimen at the base was removed (of thickness equal to about $1 \mathrm{~cm}$, i.e., about $1 / 7^{\text {th }}$ of the overall height of the specimen) and substituted by a thin disk of different material. In fact this is a different way of modifying the conditions at the base contact, not by geometrical configuration this time but by changing material properties.

Two cases were studied: Kenchreae stone specimens with a base made of Alfopetra stone and specimens made of Alfopetra with a base made of Kenchreae stone (Figure 9).

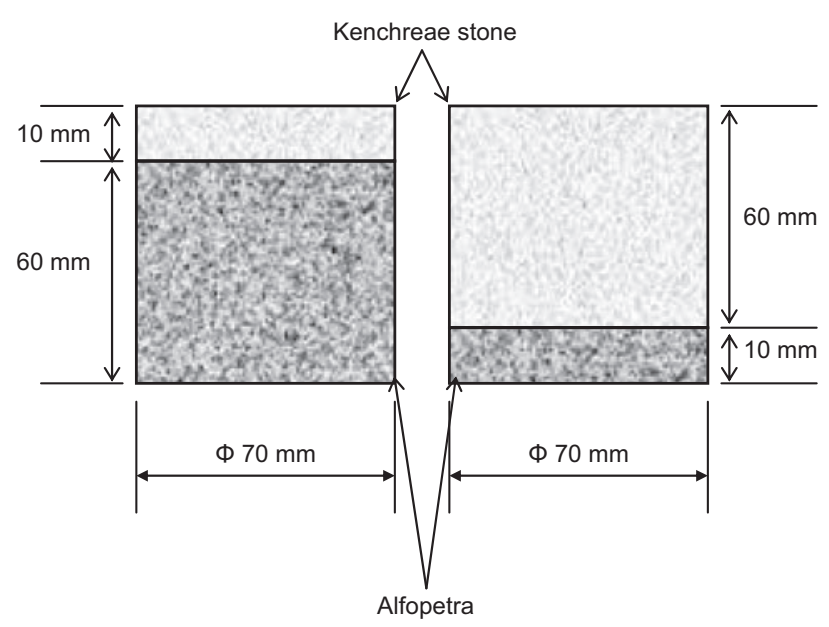

Figure 9 The configuration of the specimens with modified contact bases using patches of different materials. 
Using this class of specimens the friction conditions at the base are changed while the mass of the specimen remains essentially the same. As mentioned previously the above configuration is in effect just another kind of modification of the boundary conditions.

In case of a hard and brittle base (Alfopetra stone) attached to a specimen from a ductile rock (Kenchreae stone), the small patch of Alfopetra stone at the top adds to the rigidity of the specimen and reinforces friction effects. As a result the vertical cracks of Kenchreae stone are forced to form the familiar Mohr-Coulomb cone, as it can be seen in Figure 10. On the contrary, with soft ductile ends provided the mode of failure for the brittle material changes to that of vertical splitting. In a way it functions as the rimmed base with "ring-type" contact. It acts as an elastic spring and energy absorber, which absorbs the energy by yielding and failing, thus protecting the rest of the specimen. The base friction effects are accommodated within the soft base, and the load is distributed evenly across the section. The result is failure by vertical tension cracks along the perimeter of the specimen with little or no bulging at all. All the same, the Mohr cone is totally suppressed (Figure 10B).

In Figure 11 the corresponding stress-strain curves for the two types of composite specimen tested here are plotted. It can be seen from this figure that in the case of the Alfopetra specimen with its top base made from Kenchreae stone the overall appearance of the curve is seriously altered compared to that of pure Alfopetra specimens. In fact and up to a strain level equal to about $\varepsilon=2.5 \%$ the curves approximate qualitatively that of pure Kenchreae stone. From that point onwards as the top base is practically crushing under the applied load the load starts to increase rapidly towards the pure Alfopetra strength, without reaching it due to the cracks, which were generated.

On the contrary in the case of the Kenchreae stone specimen with a base made of Alfopetra stone the respective curve is almost identical to that of pure Kenchreae material, transposed simply to higher load levels.

Finally for both cases it is clear from Figure 11 that the weakest material plays the dominant role in the recorded behaviour irrespectively of its relatively small size. The configuration of a hard specimen with a soft top-base produces a stress-strain

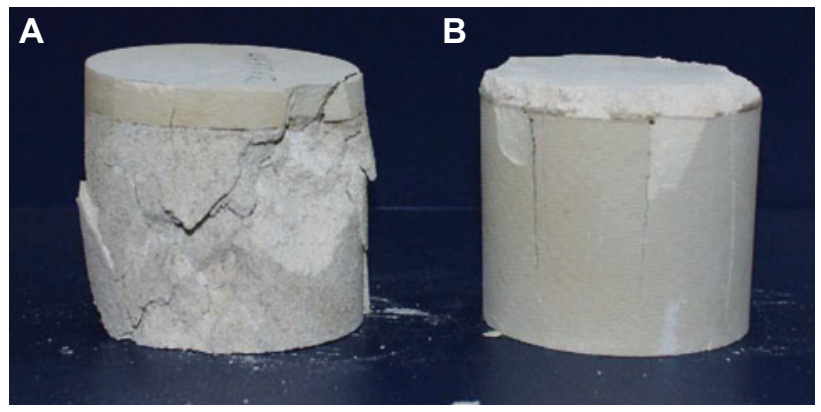

Figure 10 Tested composite specimens consisting of two parts with join plane normal to the load direction. The change of the failure modes is clearly visible in both cases.

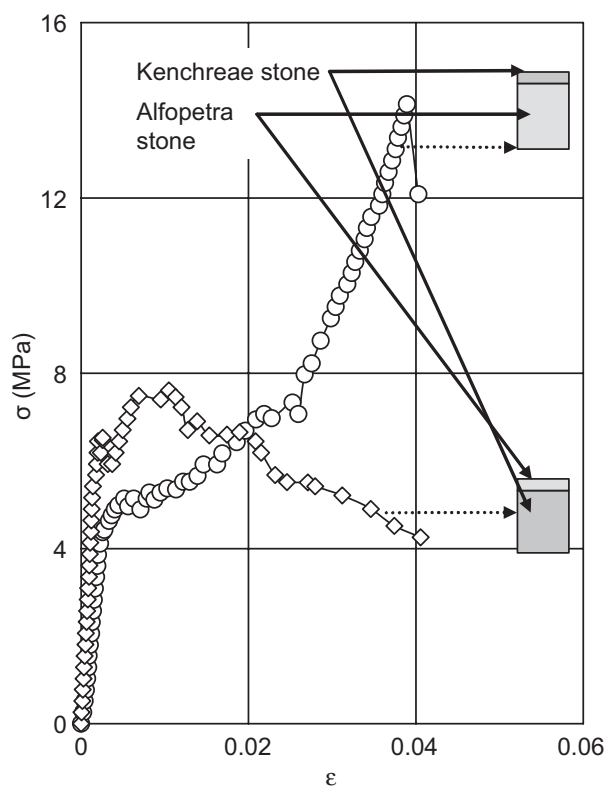

Figure 11 Stress-strain curves for both types of composite specimens tested in the present work.

curve resembling the initial part of the typical curve for metals, however at an overall lower stress level. It consists of the typical linear elastic portion up to the yield, followed by a nearly horizontal flow region leading finally to the hardening region up to the peak load. In effect, a soft base of Kenchreae stone assigns to a specimen made of a brittle material, as Alfopetra, nonelement ductile characteristics by modifying only the boundary conditions where the load is applied. The same resulted from the geometrical configuration, reported in previous paragraph, although to a far lesser degree.

\section{Specimens with modified free boundary}

A point often overlooked is the singularity introduced by the imposed abrupt change of boundary conditions of the specimen, where the friction boundary of the base meets the free boundary of the lateral surface. The combination of compression (due to friction cone) and extension (the lateral expansion produced by axial compression) makes it a favourable place for crack initiation, i.e., nonhomogeneous straining eventually leading to fracture. In trying to eliminate this effect, apart from minimising the friction at the base contact, one should also try to provide support to the free boundary against exfoliation and cracking.

It is commonly assumed that fluting in ancient columns is present due to aesthetical reasons, being one of the many architectural refinements we find in ancient Greek architecture. However, a detailed numerical analysis of the contact between adjacent drums of typical ancient columns [3] revealed that the distribution of stress concentrations along the perimeter of the stone drum during sliding corresponds to the typical fluting present in columns of ancient Greek and Roman architecture, as it can be seen in Figure 12. Hence, fluting of the columns 
might have been a conscious decision by their builders and stonemasons (based on previous evidence that such regions were prone to stone cracking and spauling), in order to prevent and control possible material deterioration at the surface. Simple engineering judgement suggests that the arched shape of the flutes resists surface cracking and acts as reinforcement. These conclusions are further supported by a recent thorough numerical and experimental analysis of specimens made from Dionysos marble, fluted according to the geometry of the flutes of the Parthenon temple, and loaded either under uniaxial compression [4], or under bending or even under shear.

Following the previous line of thought it was decided to check this hypothesis further experimentally, so a new type of specimen with modified lateral surface was introduced and studied: The specimens were modeled after the shape of column drums of the doric column of ancient Greek architecture, as was seen in Figure 3, with their lateral surface, i.e., the free boundary, fluted. Each specimen had 20 flutes exactly as is the case in the majority of ancient doric columns. The proposed configuration was tried in three out of four materials tested here, namely the Cyprus stone, the Alfopetra stone and the Kenchreae stone.

\subsection{Fluted specimens from Cyprus stone}

Two types of specimens are compared, one standard and one with flutes. The observed change, as seen in Figure 13 is striking. The peak strength is reduced by $30 \%$, the failure strain increases by more than five times and the mode of failure changes from brittle to ductile. The energy density input (the area under the stress-strain curve) for the fluted specimen is five times that of the standard one, indicating the increased capacity of the so configured specimen to absorb energy.

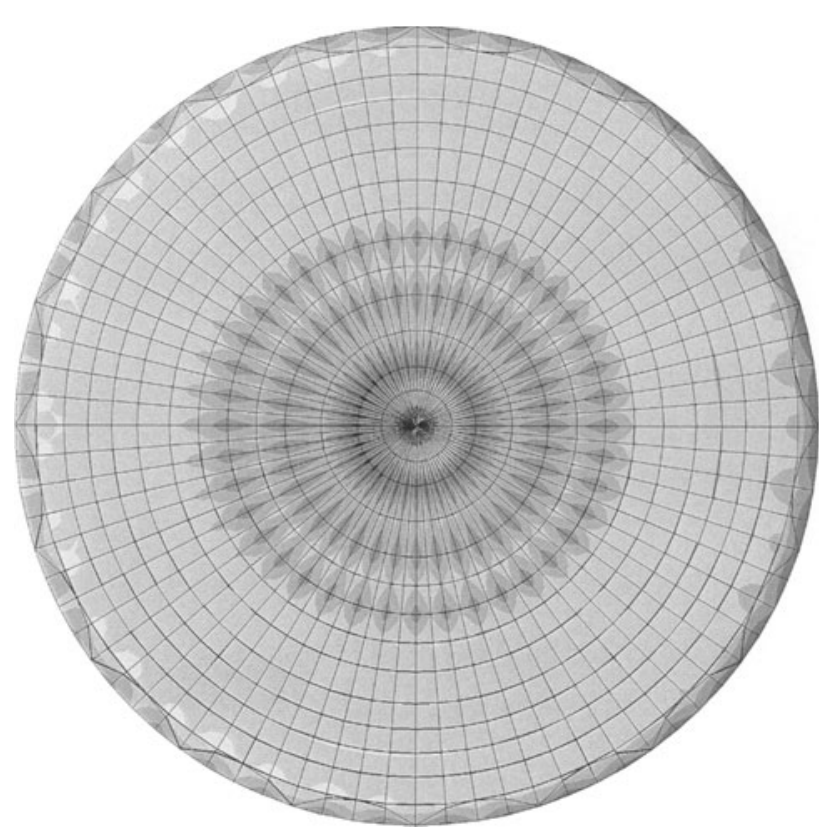

Figure 12 Von Mises stress concentration at shear sliding interface [3].

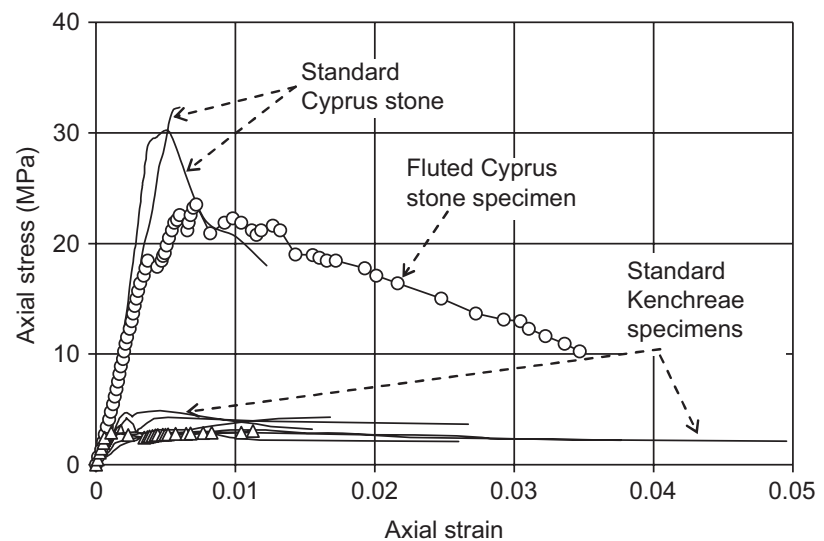

Figure 13 Comparison between standard and fluted specimens from Cyprus stone.

Overall, fluting of the lateral free boundary reduces the peak strength and adds to the stress-strain curve a large strainsoftening regime. Also shown in the same plot is the curve of a second normal specimen, which failed at a lower peak load and in a more ductile manner. This was due to a pre-existing plane of weakness in the mass of the specimen. The inherent weakness brings about premature failure (in terms of load) and gives to the specimen some "apparent" ductility. Still the mechanical behaviour of the standard specimen appears quite brittle when compared to that of the fluted specimen.

Focusing further attention to the variation of the strain energy density vs. the strain level two additional conclusions can be drawn: first, that up to a stress level of around 8-10 MPa the material in all specimens behaves almost uniformly, thus yielding "true" material properties; and second, that after this point the standard specimen exhibits a sharp increase in the rate of energy absorption due to a generalised microstructure dislocation i.e., a change in material properties. On the contrary the respective behaviour for the fluted specimen appears nearly linear up to the peak load indicating that the effect of fluting has been to keep straining and damage at microlevel uniformly distributed throughout the mass of the specimen.

Finally one more point of importance is that the specimens do not fail at macrostructural level; cracking is restricted to their lateral surface only. A characteristic fluted specimen made from Cyprus stone is shown in Figure 14 after it had been tested.

\subsection{Fluted specimens from Alfopetra stone}

In this case the fluted specimens had also their bases configured with a "ring-type" contact. The same phenomenon repeated itself in an even more dramatic way with the Alfopetra stone. The peak load, as it seen from Figure 15 was reduced to less than one third of that recorded for the usual specimens while at the same time the failure strain increased by at least four times. The significant drop in load must be attributed to the "ring-type" contact, while the increase in failure strain is purely the effect of the presence of flutes. 

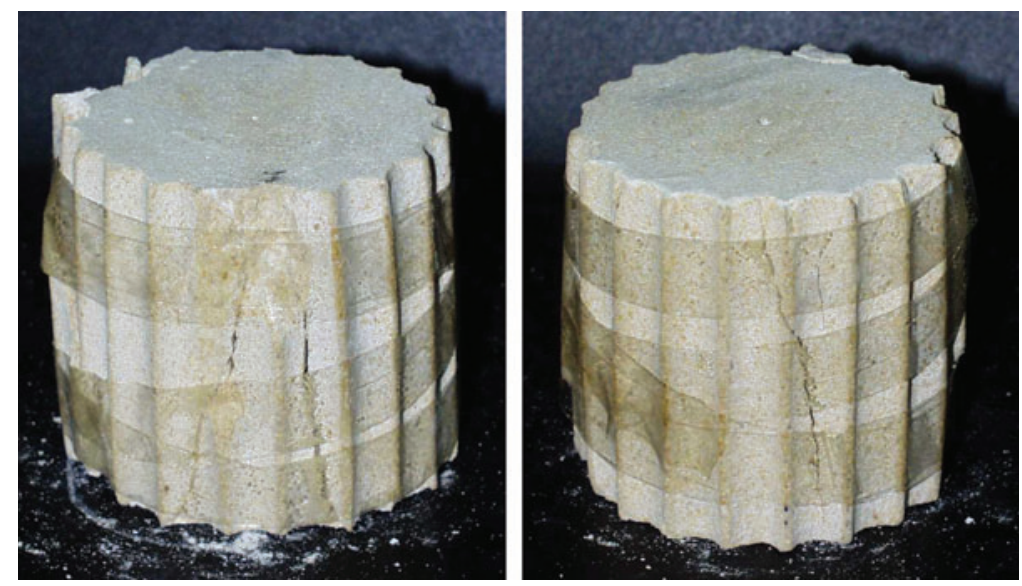

Figure 14 Characteristic fluted specimens from Cyprus stone after being tested in compression.

Concerning the energy density input (i.e., the area under the stress-strain curve) it is observed that for the fluted specimens it is almost twice that of the standard ones, and roughly equal to that of the standard Kenchreae specimen. This means that by geometrical configuration alone two specimens made of different materials have become equivalent in terms of their energy absorption ability in a standard unconfined compression test. It is therefore concluded that the fluted configuration apparently distributes the damage more uniformly in the specimen mass and thus changes the mode of fracture from brittle (almost explosive) into one of controlled cracking. As a result the specimens exhibit smaller strength and higher failure strain. A characteristic fluted specimen from Alfopetra stone is shown in Figure 16, before and after being tested.

\subsection{Fluted specimens from Kenchreae stone}

The same observations were made for the Kenchreae stone although the effects this time were less pronounced, as it would be expected due to the documented ductile nature of the material. The failure strain increases by a similar amount of about $27 \%$, as it is seen from Figure 17. The increase in strain observed

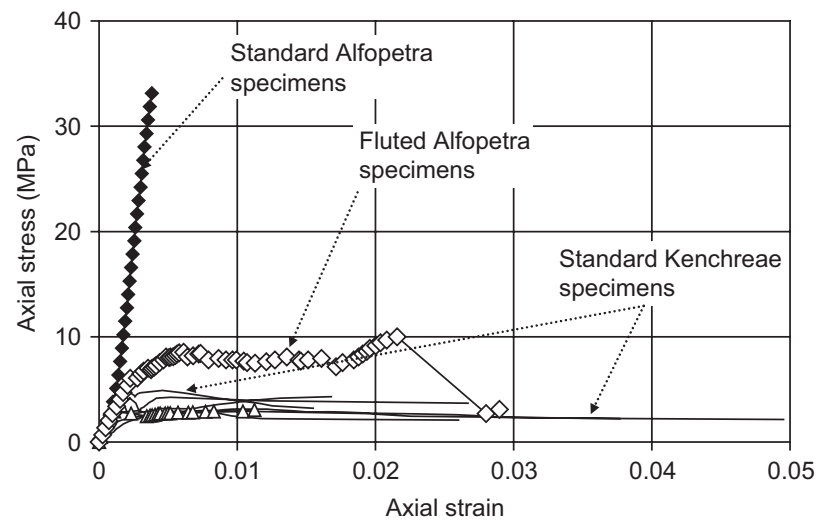

Figure 15 Comparison between standard and fluted specimen from Alfopetra stone. after the level of about $0.025 \mu$ strain is due to the fact that the contact area increased because the contact ring was gradually eliminated (Kenchreae stone is relatively weak) and the endplatens came into contact with the whole specimen base.

Again studying the strain energy density with respect to the strain level for the standard and the fluted specimens it is important to notice that the effect of fluting has been to extend the linear response of the specimen's strain energy density absorption vs. strain all the way up to the peak load, i.e., to prevent early localisation of strain and damage. A characteristic specimen is shown in Figure 18 both before and after being tested.

\section{Discussion}

Considering the experimental data presented in previous paragraphs it has become clear that in judging the compatibility of natural building stones, which are proposed for use in the restoration of ancient monuments, it is important to compare the full stress-strain curve and, if this is possible, to consider also strain-rate and relative size effects.

It is clear that a direct comparison of peak strengths is not enough and can be misleading. Each part of the curve is relevant to a different aspect of the material's function into the structure. The initial part reflects the various bedding effects, which are a real problem both in an experimental set-up but in a structure also. In the case of column drums in an ancient Greek column this is taken care of by perfecting the joints.

The next part of the curve, the nearly linear elastic one, concerns the absolutely safe working load range of the material in any structure. It is characteristic that the low strength (peak load in the range of 2-4 MPa) stones, used by ancient builders for the upper-structure in many ancient temples and sacred monuments, in general meet ideally the structural requirements, since the working load would not exceed in any case the 1-2 MPa range.

The third part of the stress-strain curve that is of interest, is the yield region. The start of partial yielding means that load is locally shed to neighboring regions of the material, thus creating an internal net of preferential paths for load transfer. 

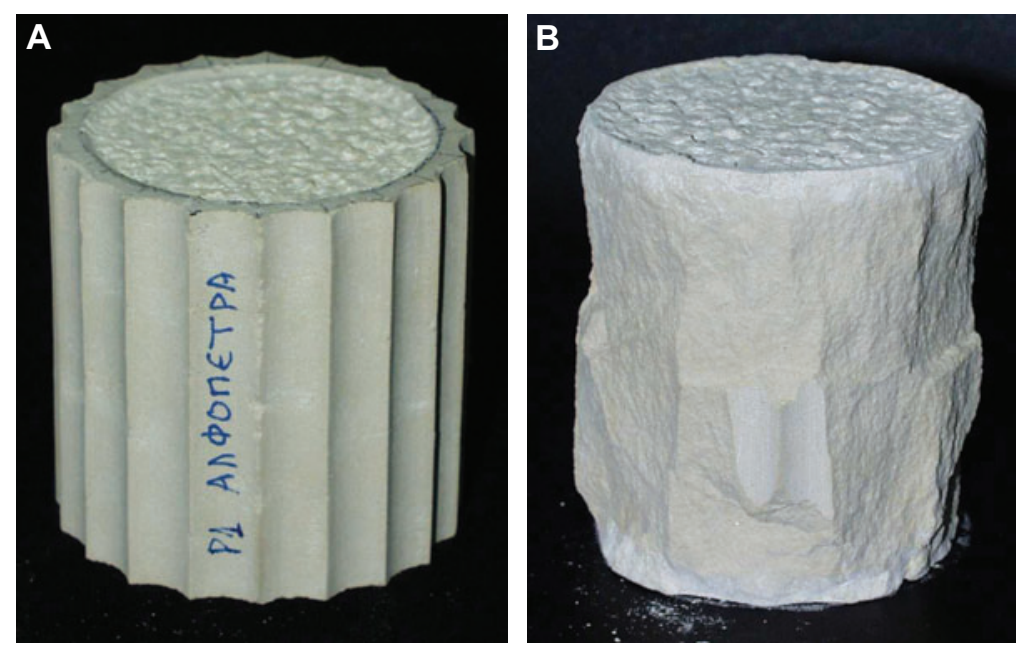

Figure 16 Characteristic fluted specimens from Alfopetra stone before (A) and after (B) being tested under compression.

This process brings into the picture the intrinsic structure of the material (anisotropy, inhomogeneities, layers of weakness, etc). At this stage the combined effect of loading, structure and boundary conditions will effectively determine the form failure is going to take. The way of failure will influence the particular architectural member and through it the whole structure. However, the extent of this region determines the energy that will be absorbed in case the structural element is overloaded.

The point is clearly made by considering the variation of the energy density with respect to the strain for standard and fluted specimens. The difference comes into play in the postyield region, when nonuniform straining in the standard specimen has started to create failure zones as it can be concluded by the accentuated rate of energy absorption rate. In addition, the linear form of the curve up to peak strength for specimens with fluting in their lateral surface suggests a steady rate of damage growth in a state of contained failure.

The mode of failure observed and recorded in an unconfined compression test, as well as the associated peak strength, is not a true material property. A difference in the mode of failure of two materials is an indication that their properties

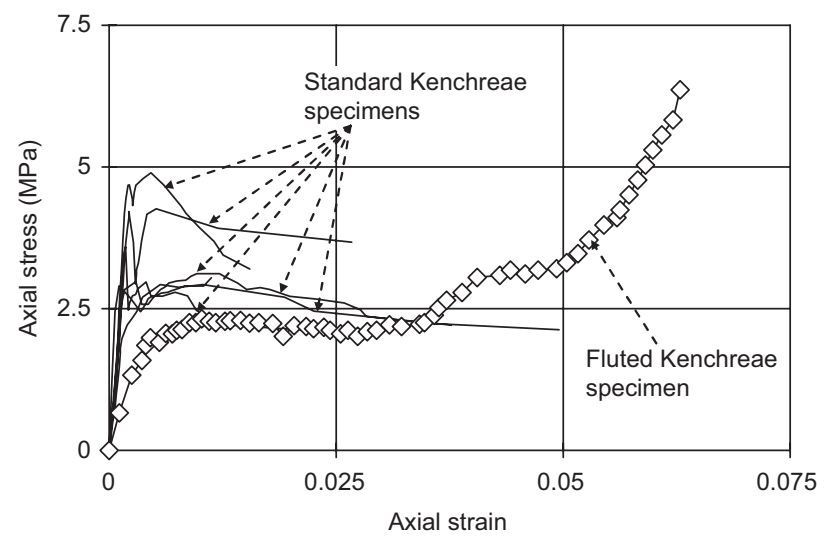

Figure 17 Comparison between standard and fluted specimens from Kenchreae stone. cannot be meaningfully compared given the characteristics and restrictions of the specific test.

It is clear that mechanical compatibility of natural building stones can be considered at different levels - the small strain region, before yield, after yield up to peak load and after peak all the way to failure. Depending on the kind of use, a different compatibility criterion can be devised. For situations where the "required" quality of the building stone is its ability to withstand deformation without failing structurally, a characteristic pertinent to statically indeterminate structures, whose design is based on deformation control, a brittleness criterion of the type described below may be proved useful. Indeed combining both peak stress and maximum failure strain provides a better indication and thus possible description indices of the post-peak region could be:

- The area underneath the stress-strain curve as a measure of the energy dissipated during failure per unit volume.

- The factor $C$ defined as the ratio of the extend of the yield zone over the peak strain:

$$
C=\left(\frac{\varepsilon_{\text {failure }}-\varepsilon_{\text {peak }}}{\varepsilon_{\text {peak }}}\right)
$$

as a measure of the relative ductility, i.e., a brittleness criterion.

Concerning the latter index, i.e., the brittleness of the material, an important point has come out from this research: Brittleness (strain-softening behaviour) and mode of failure can be altered by proper geometrical configuration of the specimen. Anticipating the results and mimicking the geometrical pattern of the stress distribution at the boundaries of the specimen appears to be an effective way of producing a marked effect in behaviour. Since the nonuniform stress distributions observed in a specimen during loading is its reaction to the imposed external loading, it is only logical to expect that by taking these into account (into the shape and the form of the specimens) the resulting behaviour will come closer to the "true" or "element" properties of the material. 

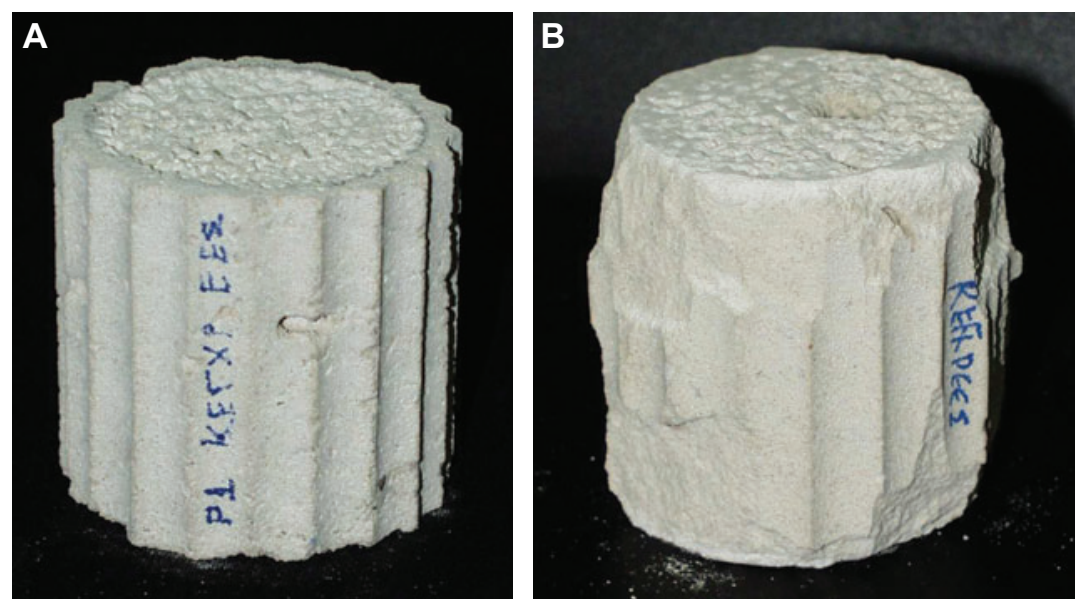

Figure 18 Characteristic fluted specimen from Kenchreae stone (A) before and (B) after being tested under compression.

Finally it should be kept in mind that the materials under study exhibit a strong dependence of their properties on the size and the shape of the specimens used for the tests $[14,15]$ and this dependence cannot be ignored when comparing the results of various experimental series realised at various laboratories.

\section{Conclusions}

The work presented has examined the determination of the mechanical behaviour of natural building stones in relation to the restoration of monuments. Several aspects have been highlighted - the importance of the material nature (brittle vs. ductile) as an important evaluation and compatibility criterion for stones, the use of qualitative estimation of the behaviour of composite specimens (and structures) and the need for clear understanding and controlling the boundary conditions both in experiment and real structure.

On the basis of the experimental observations reported here the following specific conclusions could be drawn:

- In evaluating the mechanical strength of natural building stones it is important to take into account the full stress-strain curve including post-peak behaviour of the material. It is important to know the exact nature of each material (brittle or ductile), when it comes to judging their compatibility.

- The study of composite specimens is a powerful means for a qualitative assessment of mechanical compatibility between different stones. The weaker material, which fails first, is the controlling factor of the overall behaviour. However, the mechanical behaviour of each material involved depends on the kinematical restraints imposed on it by geometry, relative size and way of loading.

- Boundary conditions at the loading interfaces, such as friction, nonuniform stress distribution at the loading surfaces as well as the detailed geometrical configuration of the contact areas are critical for the correct interpretation of experimental results and of paramount importance in simulating the real conditions in a structure using data from element tests.

- The Mohr-Coulomb cone is demonstrated to be a friction effect. Lubrication is one way to reduce friction. Modifying the geometrical configuration of the bases seems to be another equally effective way of controlling it [16].

- Comparison of mechanical properties should not be carried out under different modes of failure. Examination of the postyield and post-peak behaviour can better enlighten the way a material distributes the load induced into its whole volume.

Coming to an end it could be stated that the completion of ancient architectural members with new material, mechanically incompatible to the authentic one, has to be considered carefully based on the size, shape and position of the patch in the particular member, as well as the position of that member in the overall structure.

\section{Acknowledgements}

The financial support of the "Committee for the Preservation of the Epidauros Monuments" is gratefully acknowledged. The contribution of Mr. H. Kalaitzidis who made the fluted specimens and the willing assistance of Mr. Th. Gerakis and the late Mr. G. Karydas during the experimental procedure are also acknowledged.

\section{References}

[1] Kourkoulis SK, Ninis NL. J. Mech. Behav. Mater. 2011, 20, $39-51$.

[2] Ninis NL, Papakostopoulos N, Tsikouras B. Proceedings of International Symposium on Geological and Geotechnical Influences in the Preservation of Historical and Cultural Heritage, Torino, Italy. Lollino G, Ed. CNDCI Publishing: 2000, I, pp. 705-713.

[3] Ninis NL, Kakaliagos AK, Mouzakis H, Karydis P. Proceedings $5^{\text {th }}$ International Conference on Analysis of Discontinuous Deformation, Beer-Sheva, Israel. Hatzor YH, Ed. A. A. Balkema Publishers: The Netherlands, 2002, pp. 145-152. 
[4] Kourkoulis SK, Moupagitsoglou KE. Strain 2009, 45, 468-479.

[5] Sakellariou A. $1^{\text {st }}$ and $2^{\text {nd }}$ Interim Reports of the "Committee for the Preservation of the Epidauros Monuments" and "Testing, Research and Standards Center, Public Power Corporation" common project, Athens, Greece, 2000. (In Greek).

[6] Labuz JF, Bridell JM. Int. J. Rock Mech. Min. Sci. and Geomech. Abstr. 1993, 30, 451-455.

[7] Drescher A, Vardoulakis I. Geotechnique, 1982, 32, 291-303.

[8] Read H, Hegemier GA. Mechan. of Mater. 1984, 3, 271-294.

[9] Van Vliet MR, Van Mier JG. Report 25/5-95-9, TU Delft, Faculty of Civil Engineering. TU Delft: The Netherlands, 1995.

[10] Exadaktylos G, Vardoulakis I, Kourkoulis SK. Int. J. of Solids Struct. 2001, 38, 4119-4145.

[11] Vardoulakis I, Kourkoulis SK, Zambas C. Proceedings of the $2^{\text {nd }}$ International Symposium on Hard Soils Soft Rocks, Naples,
Italy. Evangelista A, Picarelli L, Eds. A. A. Balkema: The Netherlands, 1998, pp. 911-922.

[12] Ninis NL, Kourkoulis SK. Proceedings of the $5^{\text {th }}$ International Conference on Analysis of Discontinuous Deformation, BeerSheva, Israel. Hatzor YH, Ed. A. A. Balkema Publishers: The Netherlands, 2002, pp. 153-162.

[13] Ninis NL, Kourkoulis SK. Proceedings of the $6^{\text {th }}$ National Congress on Mechanics, Thessaloniki, Greece. Aifantis E, Kounadis A, Eds. Giahoudi and Giapouli: Thessaloniki, 2001, I, pp. 348-356.

[14] Kourkoulis SK. Strain 2011, 47(S1), e344-e356.

[15] Kourkoulis SK, Ganniari-Papageorgiou E. Construct. Build. Mater. 2010, 24, 803-810.

[16] Vardoulakis I, Kourkoulis SK, Skjaerstein A. Material Instabilities in Solids, de Borst R, van der Giesen E, Eds. John Wiley and Sons: New York, 1998, pp. 207-226. 